\title{
10 health stories that mattered: Apr. 25-May 1
}

- The auditor general of Canada identified antimicrobial resistance and poor access to health care in remote First Nations communities as problems in his 2015 spring reports. Health Canada and the Public Health Agency of Canada failed to fulfill their responsibilities to mitigate the risks posed by antimicrobial resistance, and First Nations communities in remote areas of Manitoba and Ontario do not have proper access to health services and medical transportation benefits, stated the reports.

- About 200 members of the Canadian Forces, including medical personnel, are awaiting deployment to Nepal to assist in relief efforts following an earthquake that has killed more than 5000 people. The Canadian government will also match donations made to the Nepal Earthquake Relief Fund between Apr. 25 and May 25.

- Canadians could soon be waiting longer for medical test results because of a looming shortage of medical lab technicians, warns the Canadian Society for Medical Laboratory Science. The society estimates that more than half of medical lab technicians will be eligible to retire over the next decade.

- The Thalidomide Victims Association of Canada has "grave concerns" over the lack of details about the financial support promised them by the federal government. There was no mention in the budget of the $\$ 168$ million pledged to the remaining 94 victims of the drug to provide long-term medical assistance, the group noted.

- The federal government had "virtually nothing" in its budget to improve health care and education for First Nations communities, according to former Canadian prime minister Paul Martin. Aboriginal Affairs Minister Bernard Valcourt defended the government's commitment to First Nations people, noting that the budget included \$2 million annually for mental health services in their communities.

- Proposed cuts to public health in Quebec would place massive stress on hospitals, clinics and doctors, according to the Canadian Public Health Association. It could affect public health initiatives such as antismoking campaigns and nutrition programs, and result in increases in injuries and infectious diseases, warned the association.

- Medical marijuana should not be prescribed for people under age 25 or those with addictions, with exceptions for palliative-care and seizure disorders, according to guidelines being introduced by The College of Physicians and Surgeons of British Columbia. The college will also prohibit physicians from charging patients for documents to obtain medical cannabis.

- A proposal to increase the roles of the private and nonprofit sectors in delivering long-term care in Newfoundland and Labrador has been called an attack on the public health care system by unions. Premier Paul Davis announced a public-private partnership (P3) plan that would see the government paying fees for beds in new long-term care facilities built and operated by private or nonprofit groups.

- The modest increase for health care spending in Ontario's budget may result in job losses for nurses, hospital closures and decreased drug coverage, according to health groups including the Ontario Health Coalition and the Registered Nurses' Association of Ontario. The province's health budget for 2015-16 will be $\$ 50.8$ billion, an increase of $1.2 \%$.

- Canadian parents are being asked to show support for vaccination by signing a "spread facts, not infection" petition as part of a campaign by the Children's Hospital of Eastern Ontario in Ottawa. The campaign includes a website with facts about vaccines and a social media push with the hashtag \#SpreadFacts. - Roger Collier, CMAJ

CMAJ 2015. DOI:10.1503/cmaj.109-5056 